\title{
Perceptions of Indian neurosurgeons about medicolegal issues and malpractice suits
}

\author{
${ }^{*}$ Kanwaljeet Garg, MCh, ${ }^{1}$ Ravi Sharma, MCh, ${ }^{1}$ Amol Raheja, MCh, ${ }^{1}$ Vivek Tandon, MCh, ${ }^{1}$ \\ Varidh Katiyar, MBBS, ${ }^{1}$ Chinmaya Dash, MCh, ${ }^{2}$ Rishi Bhatnagar, LLB, ${ }^{3}$ Mohan Kumar Khullar, LLB, ${ }^{3}$ \\ Bharath Raju, MCh, ${ }^{4}$ Anil Nanda, MD, MPH, ${ }^{4,5}$ and Shashank S. Kale, $\mathrm{MCh}^{1}$ \\ 1Department of Neurosurgery, All India Institute of Medical Sciences, New Delhi; ${ }^{2}$ Department of Neurosurgery, All India Institute \\ of Medical Sciences, Bhubaneswar; ${ }^{3}$ Naveen Law Firm, Advocates Supreme Court of India, New Delhi, India; ${ }^{4}$ Department of \\ Neurosurgery, Rutgers New Jersey Medical School, Newark; and ${ }^{5}$ Robert Wood Johnson Medical School, New Brunswick, New \\ Jersey
}

OBJECTIVE Despite the rising trend of medicolegal challenges in India, there is an absolute dearth of literature from India on this issue. The authors conducted a survey, to their knowledge a first of its kind, to assess the perceptions of Indian neurosurgeons about the medicolegal challenges faced in everyday practice.

METHODS An anonymous online survey performed using Google Forms was widely circulated among neurosurgeons practicing in India via email and social media platforms. The questionnaire consisted of 38 questions covering the various aspects of medicolegal issues involved in neurosurgery practice.

RESULTS A total of 221 survey responses were received, out of which 214 responses were included in the final analysis, barring 7 responders who had no work experience in India. The respondents were categorized according to their working arrangements and work experience. Out of all of the respondents, $20(9.3 \%)$ had $\geq 1$ malpractice suits filed against them. More than $90 \%$ of the respondents believed that malpractice suits are on the rise in India. Almost half of the respondents believed the advent of teleconsultation is further compounding the risk of malpractice suits, and $66.4 \%$ of respondents felt that they were inadequately trained during residency to deal with medicolegal issues. Most respondents (88.8\%) felt that neurosurgeons working in the government sector had lesser chances of facing litigations in comparison to those working in the private sector. The practice of obtaining video proof of consent was more commonly reported by respondents working in freelancing and private settings (45.1\%) and those with multiple affiliations $(61.3 \%)$ compared to respondents practicing in government settings $(22.8 \%)(p<0.001)$. Neurosurgeons working in the private sector were more likely to alter management and refer sick patients to higher-volume treatment centers to avoid malpractice suits than their government counterparts $(p=0.043$ and 0.006 , respectively). The practices pertaining to legal preparedness were also found to be significantly higher among the respondents from the private sector $(p<0.001)$.

CONCLUSIONS This survey highlights the apprehensions of neurosurgeons in India with regard to rising malpractice suits and the subsequent increase of defensive neurosurgical practices, especially in the private sector. A stronger legal framework for providing for quick redress of patient complaints, while deterring frivolous malpractice suits, can go a long way to allay these fears. There is a dire need for systematic training of neurosurgeons regarding legal preparedness, which should begin during residency.

https://thejns.org/doi/abs/10.3171/2020.8.FOCUS20592

KEYWORDS medicolegal; malpractice; consent; lawsuit; awareness; legal

$\mathrm{M}$ ALPRACTICE suits have become an integral part of medicine, and in this regard, neurosurgery is no different from other specialties. Medical malpractice litigations have not only impacted the neurosurgical community in terms of incurred high costs but also influenced the practice of neurosurgeons to the extent that reducing legal liability may become as important as patient care, if not more. Thus, rising malpractice claims are a cause for concern among medical practitioners, as the increased claims have shifted the focus from "best patient care" to "defensive medicine." $1-3$ The higher risk of litigation in neurosurgery results in an increase in apprehen-

ABBREVIATIONS INR = Indian rupees.

SUBMITTED June 30, 2020. ACCEPTED August 19, 2020.

INCLUDE WHEN CITING DOI: 10.3171/2020.8.FOCUS20592.

${ }^{*}$ K.G. and R.S. contributed equally to this work. 
sion-driven decision-making in this complex specialty. ${ }^{2}$ There is a dearth of literature addressing such medicolegal issues in India. The absence of any medicolegal database leaves the neurosurgeons with no reliable source to guide them in their practice. This survey is, to our knowledge, the first attempt to understand the perceptions and practices of neurosurgeons about the medicolegal challenges faced in India.

\section{Methods}

An online survey was conducted using the online application Google Forms. The link to the questionnaire was widely circulated on multiple occasions among neurosurgeons practicing in both the public and private sectors in India via email and social media platforms (WhatsApp, Facebook). The survey questionnaire has been provided in the Supplementary File. The respondents were completely anonymized to eliminate respondent bias. The estimated number of neurosurgeons who participated in this survey was around 1200. Responses of neurosurgeons with no prior working experience in India were excluded from the analysis. Authors who were not involved in the questionnaire design analyzed the responses (R.S. and V.K.) of the survey to avoid any researcher bias.

\section{Statistical Analysis}

The data collected from Google Forms were exported to Microsoft Excel, and statistical analysis was done using the IBM SPSS Statistics package version 20 (IBM Corp.). Data are expressed as a proportion of responses and categorized according to the respondents' working arrangements and work experience. Survey charts were prepared using Microsoft Excel and PowerPoint.

\section{Results}

We received a total of 221 responses, of which 214 were included in the final analysis after exclusion of 7 respondents who had no work experience in India. The total response rate was $18.4 \%$ (221/1200). The respondents were categorized according to their working arrangements and work experience. The working arrangements of the respondents included the following three categories: government institutions $(\mathrm{n}=101,47.2 \%)$, freelancing and private practice $(n=51,23.8 \%)$, and multiple affiliations $(n=62$, 29.0\%). Similarly, the respondents were divided into four categories according to work experience: residents $(\mathrm{n}=$ $59,27.6 \%$ ), postresidency neurosurgery experience of $<10$ years $(n=104,48.6 \%)$, postresidency neurosurgery experience of 11-20 years $(n=32,15.0 \%)$, and postresidency neurosurgery experience of $>20$ years $(n=19,8.9 \%)$. Out of all the respondents, 20 (9.3\%) had one or more malpractice suits filed against them. The comparison of perceptions and practices of neurosurgeons related to medicolegal issues has been summarized and stratified in Table 1 according to their working arrangements as well as work experience.

\section{Perceptions About Medicolegal Issues in India}

An overview of respondent perceptions about medicolegal issues, as reflected in their survey answers, is shown in Fig. 1. More than $90 \%$ of the surveyed respondents believed that malpractice suits are on the rise in India, especially in the field of neurosurgery. Almost half of the respondents believed the advent of teleconsultation is further compounding the risk of malpractice suits. Addressing medicolegal cases is considered a "hassle" by many neurosurgeons, irrespective of their work setting.

About three-fourths of respondents reported experiencing apprehension regarding their risk of involvement in frivolous malpractice suits. Freelancing neurosurgeons in the private sector felt more at risk for involvement in frivolous suits than those working in the government sector, though the difference was not statistically significant $(p=0.332)$. Moreover, $66.4 \%$ of respondents felt that they were inadequately trained during residency to deal with medicolegal issues and associated challenges in practice, which may arise later in their career.

\section{Factors Affecting the Likelihood of Malpractice Suits}

Most respondents (47.7\%) felt that most malpractice suits are filed due to negligence or miscommunication during the postoperative period. Nearly $60 \%$ of the respondents opined that spinal surgeries have higher chances of resulting in malpractice suits than cranial surgeries. Another $43 \%$ of the respondents felt that emergency cases have a higher likelihood of medicolegal issues as compared to routine cases. The majority $(85 \%)$ of neurosurgeons felt that the presence of more than one trained neurosurgeon during surgery can decrease the likelihood of inadvertent mistakes or negligence. Most respondents (88.8\%) felt that neurosurgeons working in the government sector had lesser chances of facing litigations in comparison with those working in the private sector.

\section{Consent-Taking Practices}

The survey also addressed respondent perceptions about the association of patient consent with malpractice litigation in neurosurgery (Fig. 2). Seventy-five percent of neurosurgeons had to acquire more knowledge about proper consent taking as they entered in practice after completion of their residency. This intentional acquisition of more information was more common among neurosurgeons in freelancing or private practice (80.4\%) and those with multiple affiliations $(91.9 \%)$ than those working in government settings $(63.4 \%)(\mathrm{p}<0.001)$. Most neurosurgeons reported personally taking consent (46.7\%); however, there was significant variability in responses to "Who takes the consent?" among neurosurgeons in the different work settings $(\mathrm{p}=0.004)$, as shown in Fig. 2A. Video proof of consent is more commonly taken by neurosurgeons in freelancing and private settings (45.1\%) and those with multiple affiliations $(61.3 \%)$ than those working in government settings $(22.8 \%)(\mathrm{p}<0.001)$. In view of the recent COVID pandemic, $81.8 \%$ of neurosurgeons take special consent while admitting suspected COVID patients needing surgery, to avoid medicolegal issues arising from possible delays in management pending COVID evaluation.

\section{Clinical Practices to Prevent Medicolegal Issues}

Neurosurgeon responses to survey questions regarding 


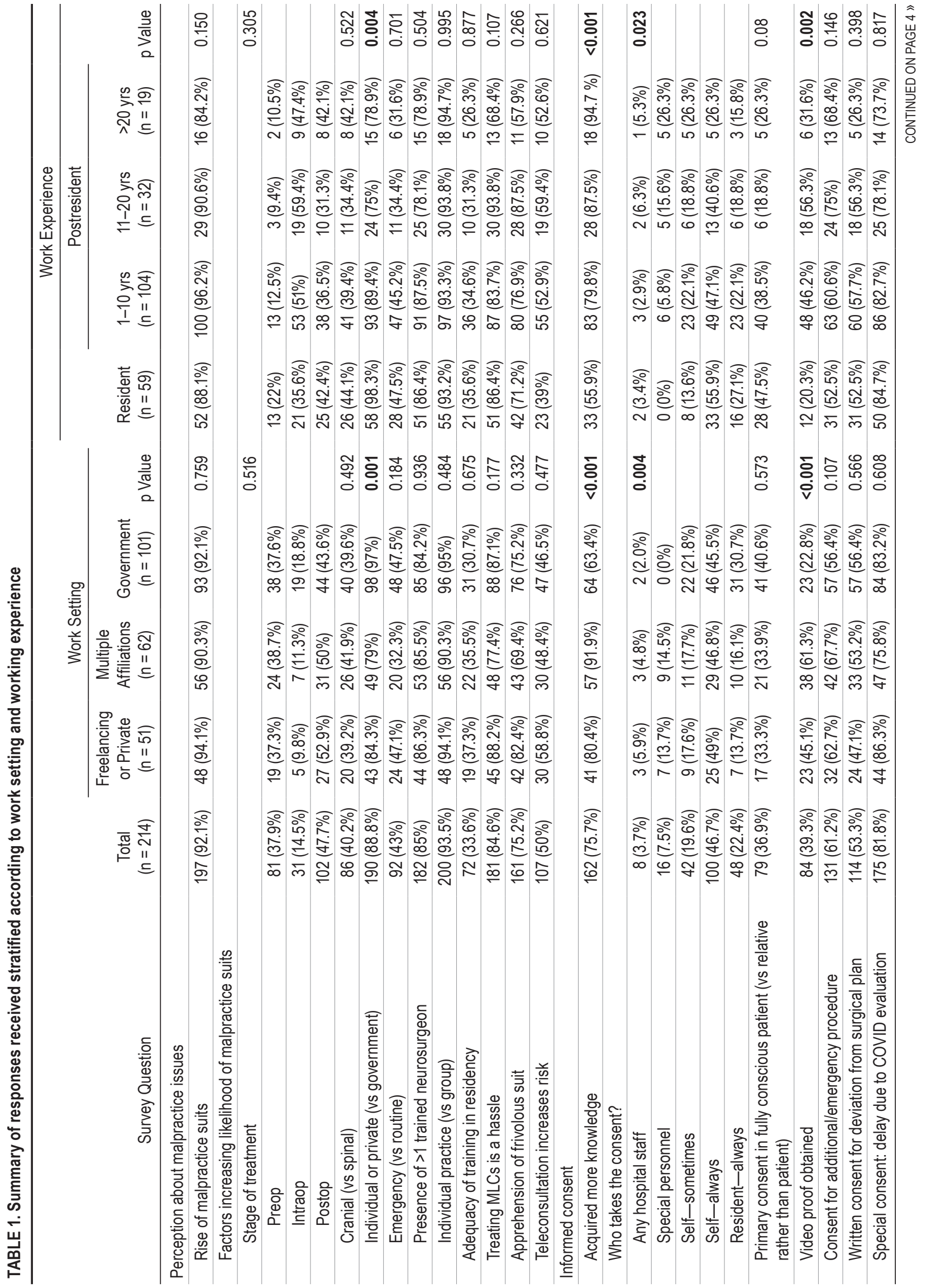




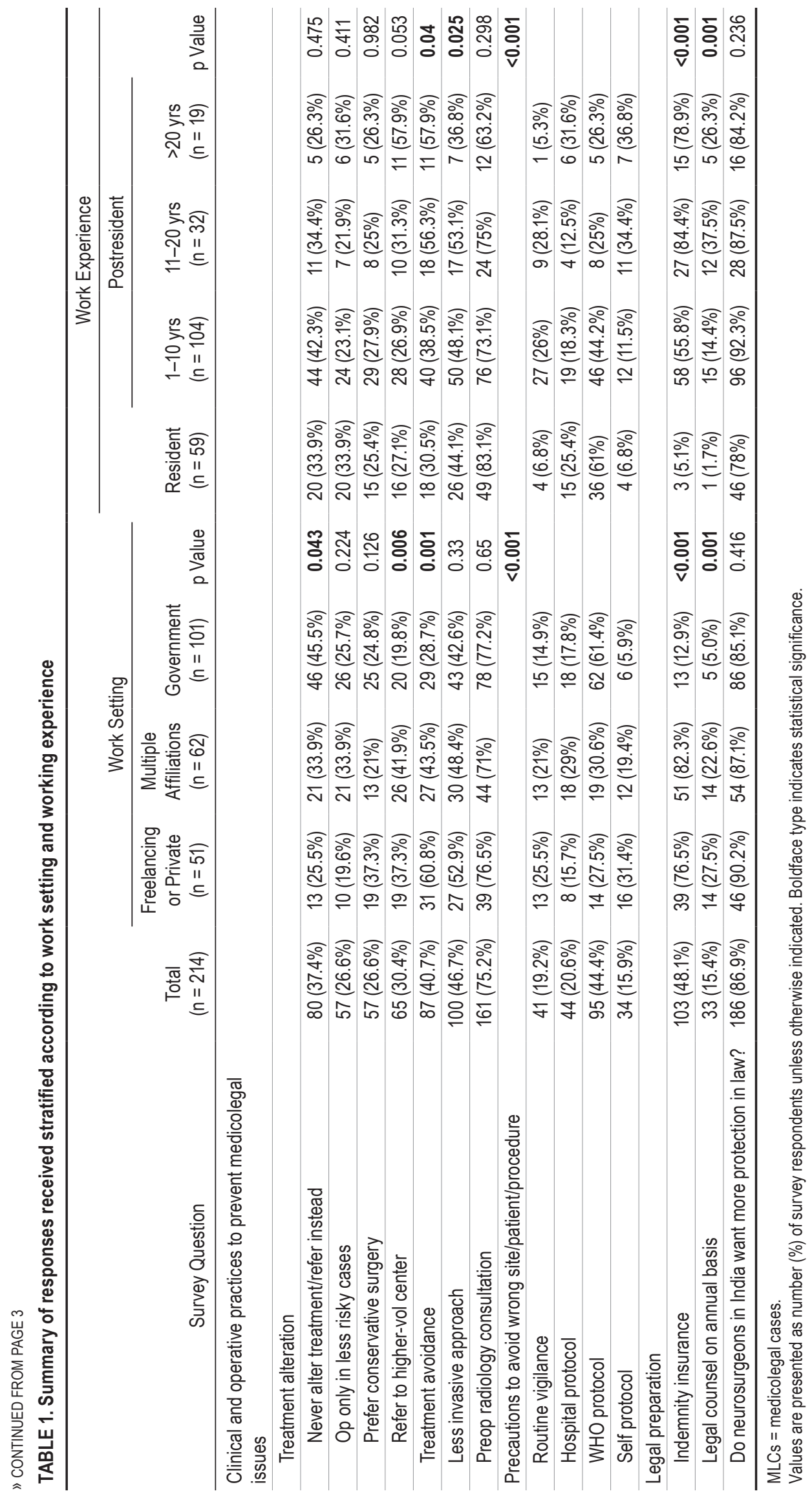




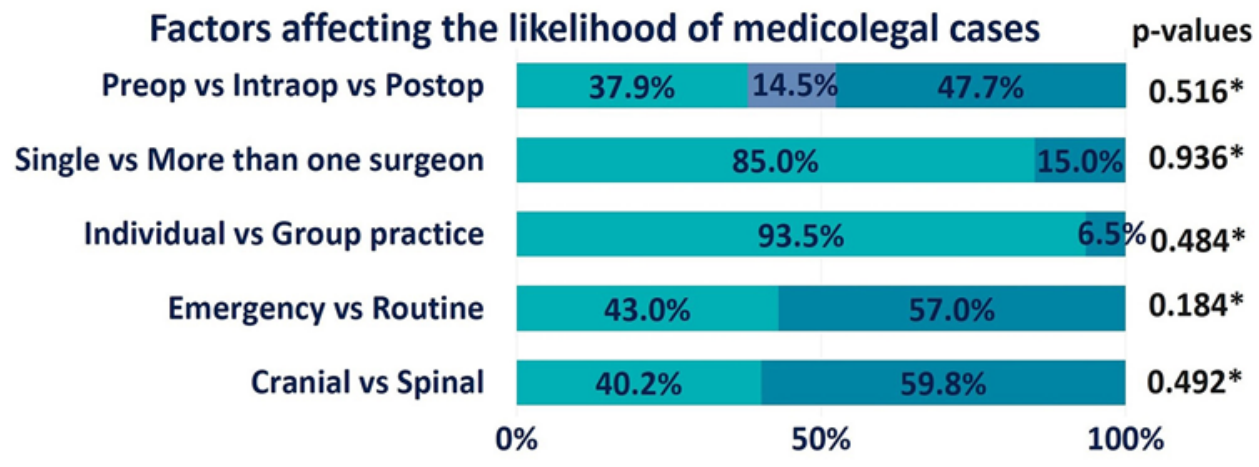

B Are you apprehensive of the possibility of a frivolous Medical Malpractice/Negligence case being initiated against you?

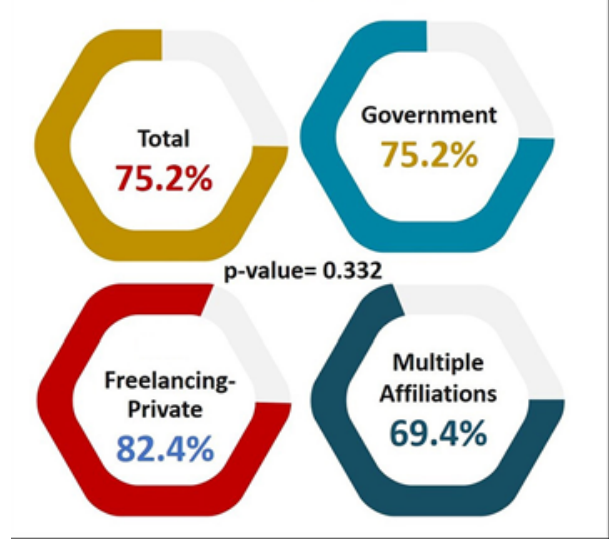

C Do you think that you are adequately trained in residency to deal with the possible medico-legal issues in your practice?

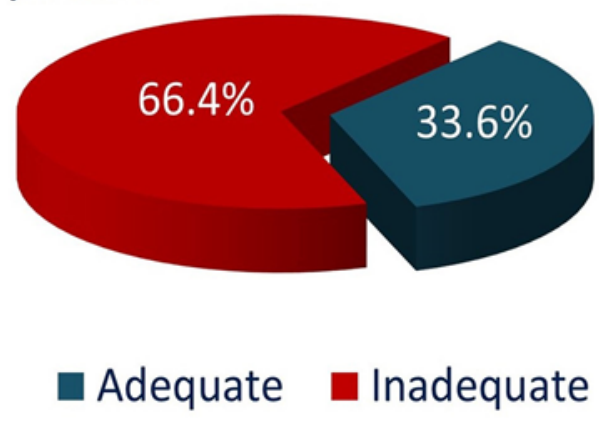

$p$-value ${ }^{*}=0.675, p$-value $\#=0.877$

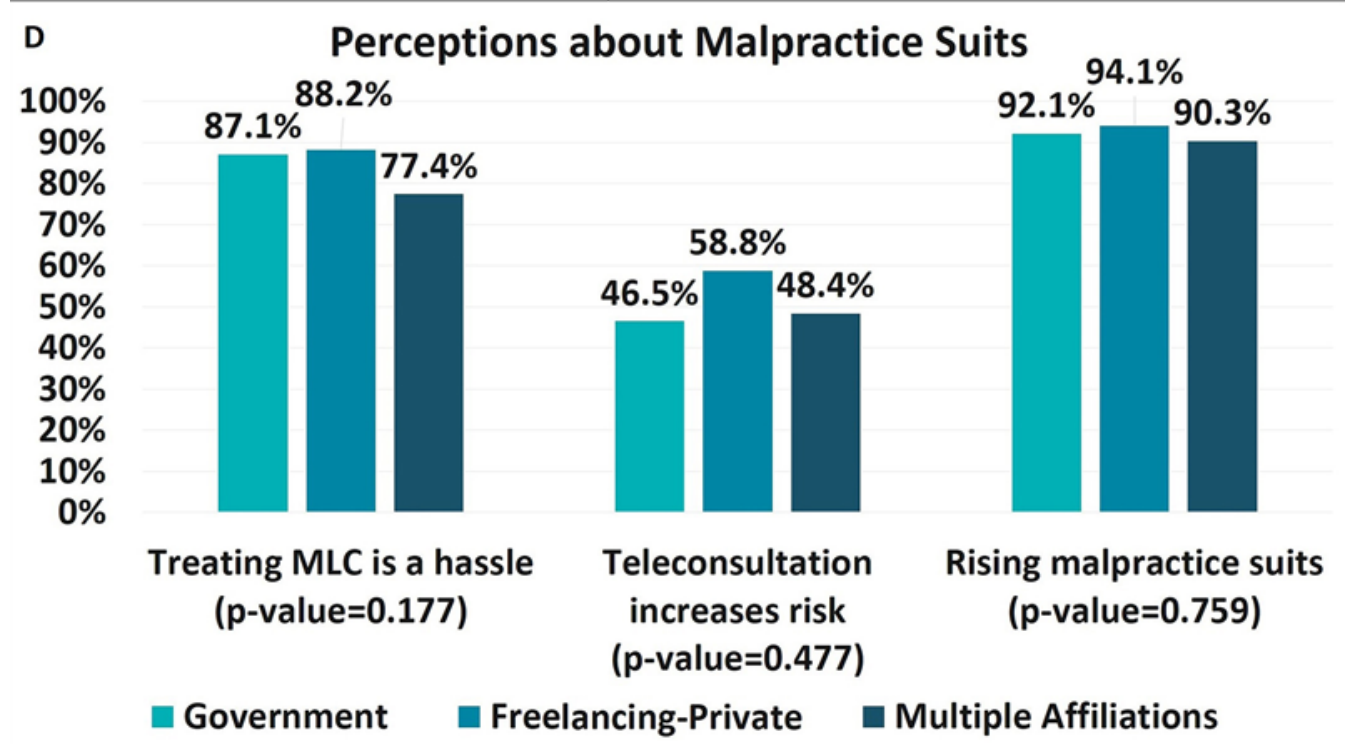

FIG. 1. Perceptions of the neurosurgeon respondents about medicolegal issues/malpractice suits. A: Factors affecting likelihood of malpractice suits. MLC = medicolegal cases. B: Apprehension regarding frivolous malpractice suits. C: Adequacy of training during residency to deal with malpractice suits. D: Other perceptions related to medicolegal issues. Significance according to work setting $\left(^{*}\right)$ and working experience (\#). 

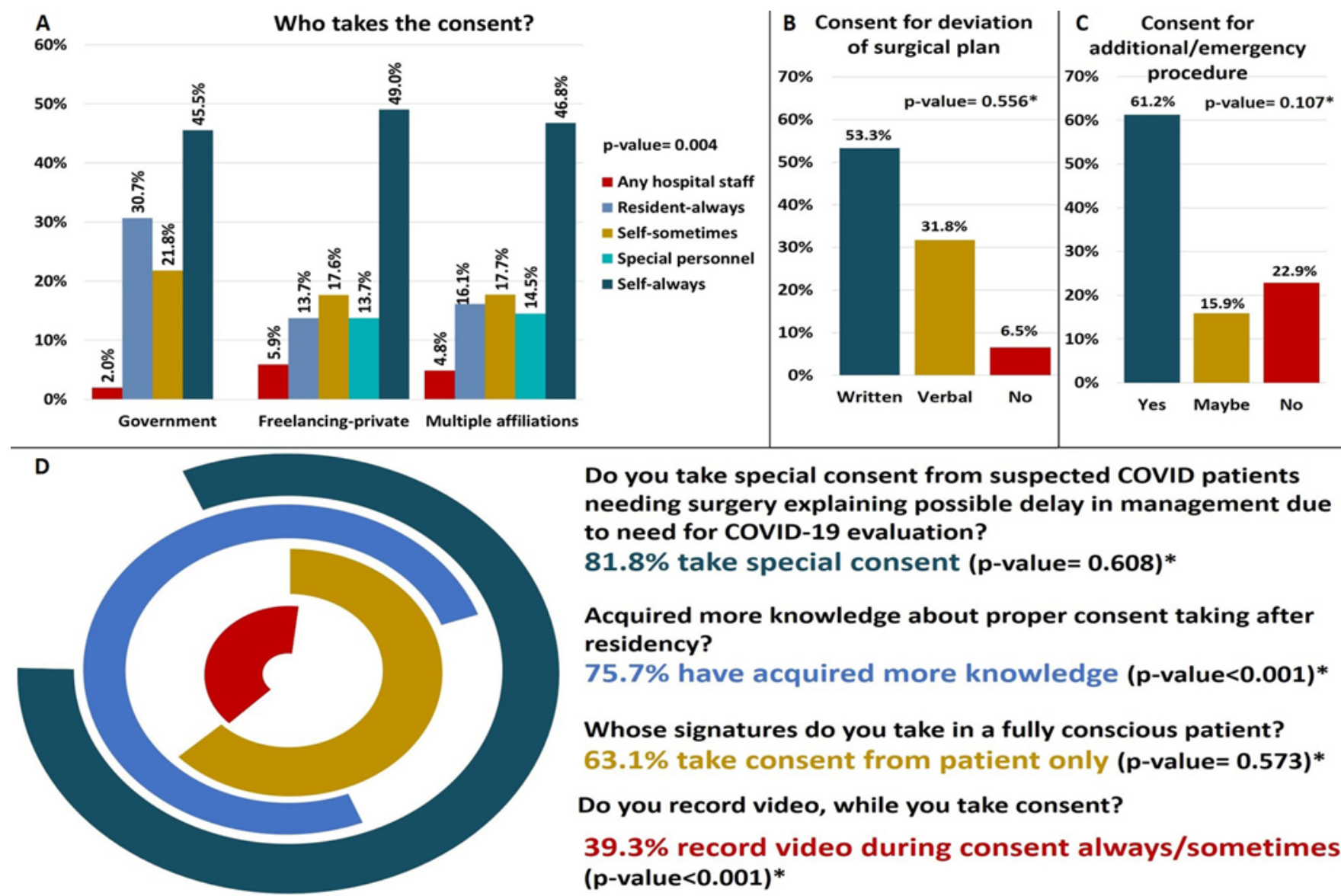

\begin{abstract}
Do you take special consent from suspected COVID patients needing surgery explaining possible delay in management due to need for COVID-19 evaluation? $\mathbf{8 1 . 8 \%}$ take special consent $(p-v a l u e=0.608)^{*}$
\end{abstract}

\title{
Acquired more knowledge about proper consent taking after residency?
}

$75.7 \%$ have acquired more knowledge (p-value<0.001)*

Whose signatures do you take in a fully conscious patient? $63.1 \%$ take consent from patient only ( $\mathbf{p}$-value= $\mathbf{0 . 5 7 3}$ *

Do you record video, while you take consent?

\section{$39.3 \%$ record video during consent always/sometimes (p-value $<0.001)^{*}$}

FIG. 2. Consent-taking practices among the neurosurgeons to decrease the risk of malpractice suits. A: Who takes the consent in different work setups. B: Consent taken for deviation from the preoperative surgical plan. C: Consent taken for additional or emergency procedure. D: Other consent-related questions. Significance according to work setting $\left({ }^{*}\right)$.

measures to protect themselves from being adversely affected by malpractice litigation are shown in Fig 3. Neurosurgeons working in the private sector are more likely than their government counterparts to alter management and refer sick patients to high-volume centers with greater expertise because of fear of malpractice suits $(\mathrm{p}=0.043$ and 0.006 , respectively). Similarly, $60.8 \%$ of neurosurgeons working in the private sector and $43.5 \%$ of those with multiple affiliations prefer not to manage or operate on patients for whom they think that the chances of becoming involved in medicolegal issues are high. This figure was statistically significantly higher for neurosurgeons in these settings than those working in a government setting $(\mathrm{p}=0.001)$. In the government setting, neurosurgeons are more likely to use the standardized WHO protocol to avoid wrong-site, wrong-procedure, and wrong-patient surgery, while those in other settings reported the use of specific hospital policies or self-protocols for the same ( $p$ $<0.001)$.

\section{Legal Preparation}

Of the 20 respondents who had faced a malpractice litigation in the past, 15 (75\%) had indemnity insurance, and 7 (35\%) had hired legal counsel on an annual basis, rates that are significantly higher than those of respondents without a history of malpractice suits ( $p=0.049$ and 0.038 , respectively). These practices pertaining to legal preparedness were also found to be significantly higher among the respondents from the private sector than among those working in the government sector $(\mathrm{p}<0.001)$ (Fig. $3 \mathrm{C}$ and D). We also found that most of the respondents (86.9\%), irrespective of their work setting, feel the need for more legal protection against the increasing prevalence of malpractice suits.

\section{Awareness Regarding Medicolegal Aspects}

With this survey we also tried to assess the awareness of neurosurgeons about Indian law pertaining to medicolegal issues. As illustrated in Fig. 4, we observed that with increasing work experience, neurosurgeons feel they are more knowledgeable about the legal defense process $(\mathrm{p}<$ $0.001)$ and liabilities under civil law $(p=0.05)$. Neurosurgeons in the private sector are likely to pay more attention to the minutiae of the terms and conditions of their contracts $(\mathrm{p}<0.001)$.

\section{Epidemic Diseases (Amendment) Ordinance}

According to our survey, $84.1 \%$ of the respondents were aware of the Epidemic Diseases (Amendment) Ordinance 
A Do you alter your treatment, due to rising legal challenges?

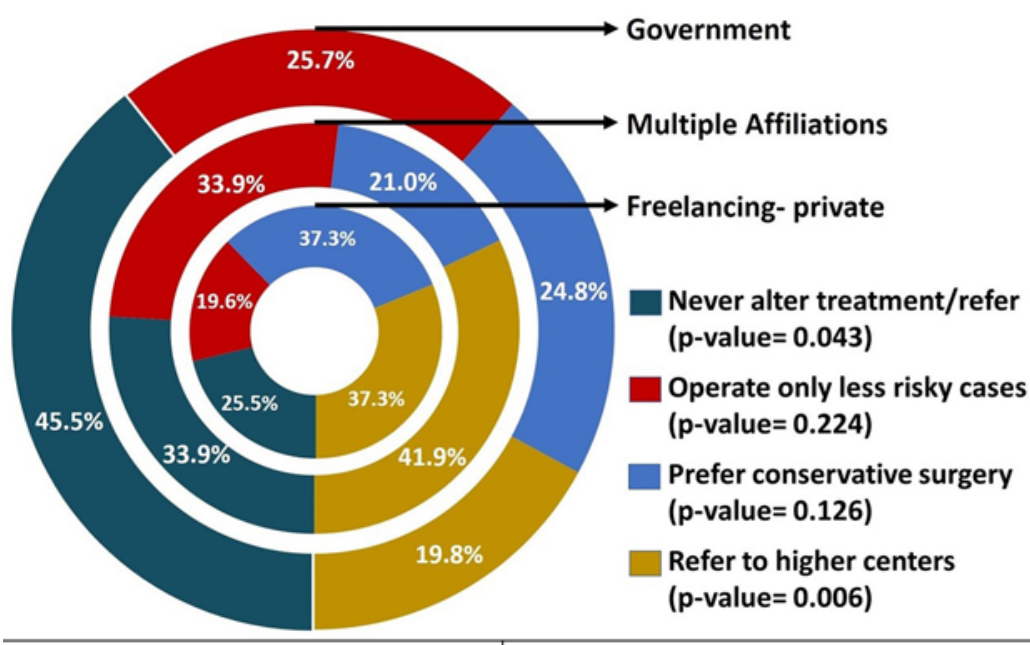

\section{$\underset{70 \%}{C}$ Indemnity Insurance}

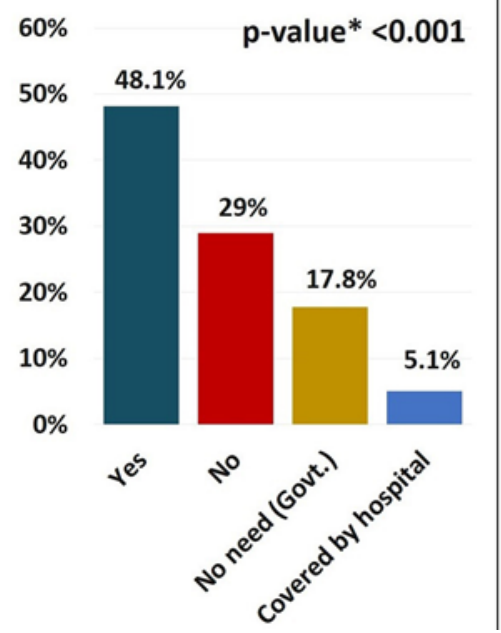

\section{Hiring of legal counsel on annual basis} $70 \%$ $60 \%$ $50 \%$ $40 \%$ $30 \%$ $20 \%$ $10 \%$ $0 \%$

$67.3 \%$

B Have you ever opted not to a manage/operate

a case fearing a medico-legal issue?

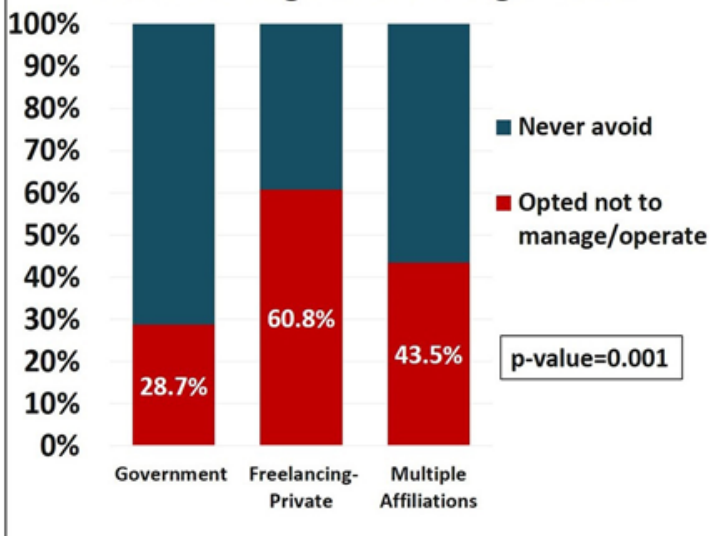

E Have you ever changed your surgical decision and opted for a less invasive or more safe procedure fearing a medico-legal issue later on?

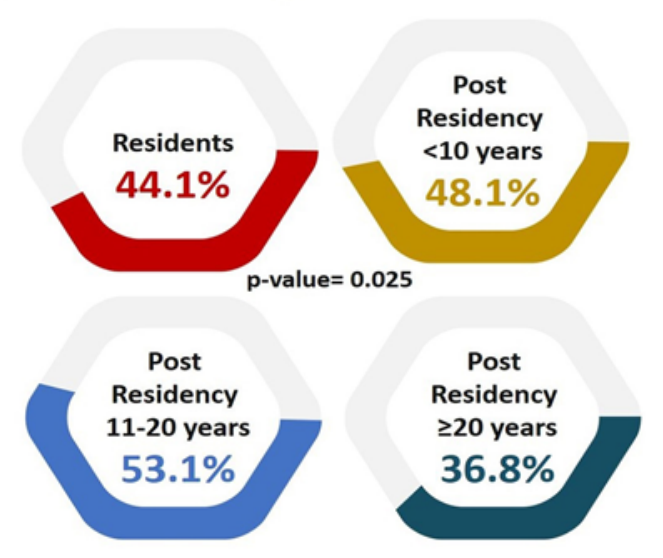

FIG. 3. Clinical and operative practices among the neurosurgeons to reduce medicolegal issues. A: Alteration of treatment to avoid medicolegal issues according to work setting. B: Avoidance of treatment to avoid medicolegal issues according to work setting. C: Proportion of neurosurgeons having indemnity insurance. D: Proportion of neurosurgeons who hire legal counsel on an annual basis. E: Altering the surgical plan or choosing a less invasive or safer approach to avoid medicolegal issues. Significance according to work setting $\left({ }^{*}\right)$.

established by the Indian government in $2020,{ }^{4}$ which is aimed at protecting healthcare professionals against violence or harm during health crises such as the COVID-19 pandemic. Similarly, $62.1 \%$ were aware of the terms of punishment and compensation under this act. More than $80 \%$ of neurosurgeons wanted similar amendments to laws protecting doctors even during nonpandemic periods.

\section{Discussion}

Among the medical specialties, neurosurgery faces unique challenges in view of the intricate nature of the surgeries performed, poorer prognosis of patients, greater postoperative morbidity, and higher cost of neurosurgical treatment. ${ }^{5}$ Thus, neurosurgeons seem to be at a higher risk of facing medicolegal issues and malpractice suits. The current body of literature regarding medicolegal issues in general, and pertaining to neurosurgery in particular, is primarily from developed countries..$^{6-8}$

\section{Comparison of Medicolegal Issues in the United States and India}

In the US, the annual risk of the practitioner being sued is less than $20 \%$, with a likelihood of a neurosurgeon making a payment through either judgment or settlement of less than 5\% per year. ${ }^{9}$ The US Congress passed the Health Care Quality Improvement Act (HCQIA) in 1986, which later led to the establishment of the National Practitioner Data Bank (NPDB). It is a web-based repository of reports submitted by registered, authorized entities like hospitals, 
Awareness trends about medicolegal aspects among Indian neurosurgeons

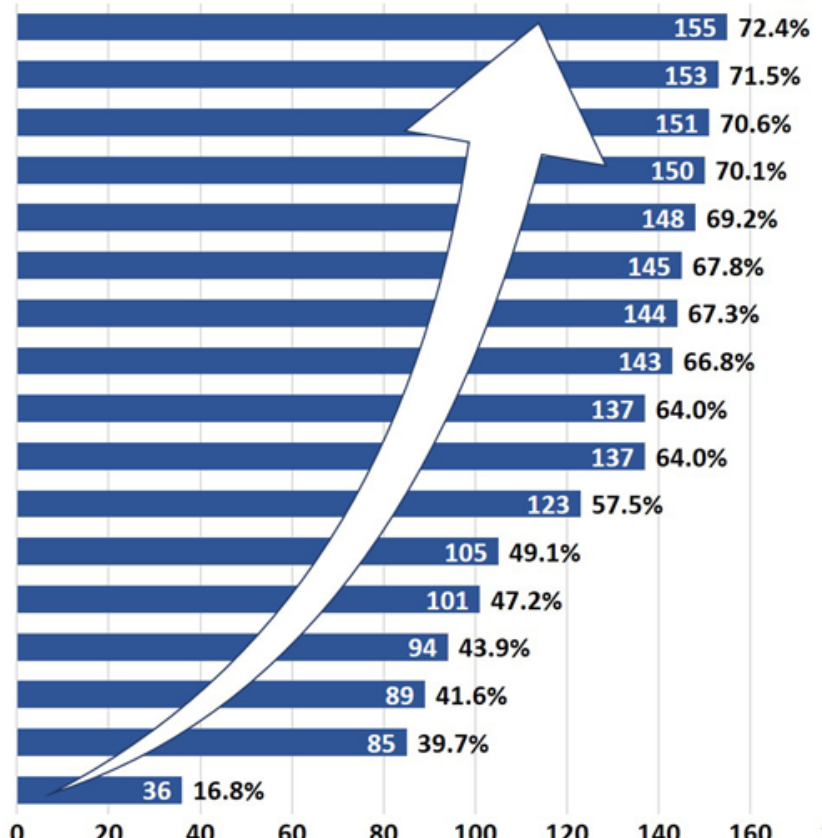

Definition of negligence

Simultaneous liability under criminal and civil law

\$ IMC act, 1956

Difference in opinion is not negligence

Liabilities under CPA, 2019

Multifaceted responsibility

Duties of a doctor

IMC Regulation, 2002

\# Liabilities under civil law

Vicarious responsibility

\$ Liability of error of judgment

*\# Terms of contract

Definition of standard of care

Definition of criminal negligence

Need for independent medical opinion in criminal negligence case

\#\$ Legal defense process

Bolam test

FIG. 4. Awareness trends among the neurosurgeons in India regarding legal aspects of their practice. Significance according to work setting $\left({ }^{*}\right)$, working experience (\#), and history of malpractice suit (\$). CPA = Consumer Protection Act; IMC = Indian Medical Council.

health plans, medical malpractice payers, state licensing boards, etc. These reports contain information regarding adverse actions, medical malpractice payments, and judgments and convictions. This system allows individual practitioners to self-query and authorized organizations to query similar litigations and judgments while involved in malpractice suits against them or their caregivers. Such databases enable assessment of the exact burden of medicolegal cases and probably will guide the organizations and the individuals to implement and follow policies, respectively. ${ }^{10}$ The Westlaw legal database is a comprehensive compilation of court documents and records concerning various medicolegal issues in the US and helps to maintain awareness among physicians as well as lawyers. ${ }^{11}$

In India, however, there is no such systematic database to guide the physicians in legal issues affecting their practice. In this age of information, malpractice suits against doctors in India are increasing at an alarming rate. Most neurosurgeons, working in all settings, who participated in this survey expressed their concern about this increase. This rising trend of malpractice suits in India can be attributed to a myriad of reasons, such as improving educational standards of healthcare seekers and hence their knowledge of their rights, increasing healthcare costs, corporatization of medical practice, corruption among doctors, and proactive lawyers. Biased and adverse reporting by the media is also an important cause for such cases. ${ }^{5,12,13}$ Moreover, incomplete information, which is readily available in print or online media to the public, makes patients more likely to doubt the professional opinion of a doctor. ${ }^{14,15}$ Many of these malpractice issues were practically unheard of 20 years ago in India, and the Indian medical education sys- tem has never been geared to impart knowledge on this front to the graduating students.

Litigations against doctors are increasing in India. ${ }^{16} \mathrm{~A}$ whopping $400 \%$ rise has been reported over the last decade. ${ }^{17}$ In 2018, around 3000 cases were filed in the National Consumer Disputes Redressal Court (NCDRC). In the absence of subcategorization, the number of medical malpractice cases could not be identified. On the basis of the personal experience of R.B. and M.K.K., who are senior advocates in the honorable High Court and the Supreme Court of India, $60 \%-70 \%$ of cases are settled out of court through an arbitration process because the Indian judicial system is complex, costly, and time consuming. ${ }^{18}$ For reasons of confidentiality, data on the quantum of claim settlements in these cases are not readily available. Courts and tribunals in India are relatively conservative regarding high-value claims. A 2008 report shows that doctors were held liable in $61 \%$ of cases filed, with an average compensation of around 300,000 to 500,000 Indian rupees (INR) (approximately 6600 USD) per each successful case, showing an upward trend over the years. ${ }^{19}$ Cumulative amounts paid over the years by doctors and doctors and hospitals together amounted to around $60 \%$ of the total compensation awarded. A new report found that only $15 \%$ of litigations related to medical negligence are genuine; this is a matter of grave concern. ${ }^{20}$

Unlike in the US, in India the cost of medical malpractice insurance is still covered under broader professional indemnity insurance. The cost of these insurance policies depends on many factors, like specialty, previous claims, doctor experience, caseload, place of work, etc. The annual premium varies greatly and the minimum annual premium 
for a newly graduated neurosurgeon is approximately 400 USD. The maximum amount covered varies somewhere between 60,000 and 130,000 USD. On average, for a neurosurgeon with 10 million INR (approximately 135,000 USD) coverage, the annual premium is around 13,000 INR (approximately 170 USD). The premium also varies depending on the number of covered claims one wants to opt for each year. There is a limit of four claims each year, and the premiums will be higher for such policies. ${ }^{21}$ Also, policies provide coverage for claims during the policy period only. That means if the physician changes insurers, or a previous patient raises litigation, the physician is not covered despite having a policy at that point in time. Many neurosurgeons do not have insurance, especially in the government setting, and they must pay the penal amounts out of their pockets.

India does not have a jury system that determines culpability or quantum of compensation. In India, the judge in the court has complete discretion over the compensation amount. There is no capping for malpractice claims in India. So, paying out of pocket after judgments or out-ofcourt settlements is not unusual. There have been at least three significant judgments in India for which doctors and hospitals were made to pay more than 10 million INR (approximately 130,000 USD), the highest being 110 million INR (approximately 1.47 million USD). ${ }^{22-24}$ Interestingly, two of those patients were doctors themselves, and none of the cases involved neurosurgeons.

Compensation amounts this large (1.47 million USD) are not covered by any insurance company in India. Based on this benchmark judgment by the Supreme Court of India, lower courts can also decide to award such high compensation amounts in the future.

\section{Telemedicine}

Compared with pre-COVID-19 times, teleconsultations via telemedicine technology have seen an exponential rise during this pandemic phase. ${ }^{25,26}$ The lack of a legal architecture to deal with disputes arising out of teleconsultations has left neurosurgeons in the lurch. Teleconsultations can lead to improper evaluations and drug prescriptions and communication gaps, potentially exposing a neurosurgeon to a malpractice suit. ${ }^{15}$

In the US, with respect to telemedicine and teleconsultation, the Health and Human Services (HHS) Office for Civil Rights (OCR) has issued guidance to empower healthcare providers to serve patients by removing previous restrictions governed by the Health Insurance Portability and Accountability Act (HIPAA) during the COVID-19 national public health emergency. The US Centers for Medicare and Medicaid Services also released a list of services payable under telehealth. This allowed neurosurgeons to consult their patients by hospital telehealth platforms as well as public platforms like Facebook, WhatsApp, Zoom, WebEx, etc. ${ }^{27,28}$ However, such a system is not possible in India because the majority of patients, especially in government-run hospitals, do not have health insurance. All health insurance schemes, especially government-run schemes, never provide a remuneration for an outpatient consultation. Thus, there is no motivation for the neurosurgeons and, in fact, a risk from a medicolegal perspective with regard to telemedicine practice. Another problem with telehealth in India is that it may further overwhelm the already exhausted hospitals with added telehealth cases, rather than equally distributing them. Hence, there is a need in India for comprehensive healthcare reform laws like the Affordable Care Act (ACA) in the US. ${ }^{29}$

\section{Differences in Perceptions of Public Versus Private Practitioners in India}

This survey has revealed the differences in the perceptions and practices of neurosurgeons working in different settings in India. Those working in the private sector are generally more apprehensive about medicolegal issues, which is reflected in their practices of educating themselves on legal aspects of consent, such as personally documenting and recording videos of the process. Many neurosurgeons, especially those in government settings, are forced to see more patients than one can safely handle in a given amount of time. This kind of workload can obviously lead to suboptimal care and increases one's vulnerability to facing judicial scrutiny. The judiciary system usually does not consider these facts while pronouncing judgments, and therefore, due caution must be taken while seeing patients.

\section{Defensive Medicine: A Rising Trend due to Medicolegal Suits and Violence Against Doctors}

A higher prevalence of medicolegal issues and the rising trend of violence against doctors in the private sector have been reported to possibly bias neurosurgeons to practice "defensive medicine." ${ }^{30}$ Our survey reveals similar facts. As a result, neurosurgeons working in the private sector prefer to treat patients with a lesser risk of postoperative morbidity or mortality or opt for more conservative surgery to avoid complications. Physicians are significantly more likely to refer patients to a higher-volume center for further management if they deem the pathology too risky. Among our survey respondents, the tendency to avoid necessary intervention is greater among freelancing private practitioners $(60.8 \%)$ compared with government neurosurgeons (28.7\%). In a specialty like neurosurgery, in which morbidity and mortality are higher in comparison with the rest of the medical field, the practice of defensive medicine can pose significant health risks to prospective patients. ${ }^{31}$ Violence against doctors is another burning problem which requires a quick redressal in our country. ${ }^{18,32}$ The government of India took notice of this rising trend and quickly amended the Epidemic Diseases Act of 1897 on April 22, 2020, via an ordinance to provide protection to healthcare workers during the COVID-19 pandemic. ${ }^{4}$ Most doctors who were surveyed have conveyed their desire to have a similar protective legal framework in place during nonpandemic times as well.

This survey also highlights the inadequate awareness about legal issues as well as inadequate legal preparedness among neurosurgeons. Those who have faced malpractice suits are likely to have indemnity insurance or hire legal counsel. Most corporate hospitals hire legal firms to handle their medicolegal issues. However, due to a lack of awareness and the costs involved, many neurosurgical practitioners prefer to hire lawyers on a case-by-case basis. 
Some neurosurgeons in India tend to avoid cases for which they are likely to encounter legal challenges. The reasons for this avoidance are manifold, involving financial, legal, and infrastructural issues, violence against doctors, subsequent loss of property, or mental agony. Patients with high-risk cases like motor vehicle accidents and severe assaults are more likely to have long-term hospitalizations with poor outcomes, draining patient resources and creating distrust and unnecessary litigations against neurosurgeons. Unlike in the US, in India a neurosurgeon involved in malpractice litigation is expected to attend court personally, as a witness or to provide an expert opinion regarding a patient they have treated. The role of expert witness is especially difficult for neurosurgeons in private practice, who are working on a fee-for-service basis. The compensation offered by courts to doctors for appearing as witnesses is negligible; thus, many neurosurgeons might prefer to avoid these situations. Neurosurgeons in government practice find themselves able to more confidently provide the best treatment according to their professional opinion without fear of litigation, as the treatment is free or affordable in government hospitals and the chances of getting sued are less for neurosurgeons. Moreover, for government doctors, court duty does not amount to monetary loss.

\section{Good Practices to Avoid Medicolegal Hassles}

Knowledge of jurisprudence can help neurosurgeons practice better, collaborate proactively with legal counsels, and be more successful in public conversations about treatment-related issues with the patients and their relatives. ${ }^{32}$ These issues are inadequately dealt with during residency programs in India. We believe a good foundation can be laid by making residents aware of rising legal challenges by discussing case-based scenarios to improve their medicolegal knowledge. Discussions of medicolegal cases in India in which other neurosurgeons were involved will help doctors starting their careers to make appropriate decisions later in life. We recommend improving the curriculum by inclusion of a few extra lectures on this topic by experts in the field. Lectures should also focus on improving communication skills, as not all residents are good communicators, and many need to learn this art. ${ }^{33}$ Constructive criticism of fellow colleagues regarding patient care issues should be restricted to scientific gatherings such as mortality and morbidity meetings only, and these ethics should also be instilled during initial training. Accepting help from fellow neurosurgeons in difficult cases can ease one's burden and decrease chances of litigation. We also demand a better legal framework in India to make the judicial system more efficient, decrease frivolous suits, and protect doctors against violence.

\section{Limitations}

Although to our knowledge the survey we report here is the first to assess medicolegal aspects among neurosurgeons in India, there are a few limitations of our study. The survey we used was an anonymous cross-sectional survey, which consequently was prone to self-reporting bias. The distribution of neurosurgeons into the different work settings and working experiences is not proportionate to the true population distribution, resulting in sampling bias.
Considering that we found significant differences among the responses according to both work setting and experience, this sampling bias would likely distort the overall survey results. Nevertheless, the survey sheds light on an important topic that deserves much more attention than it currently gets in a lower-middle-income country like India. The lack of information discovered brings to attention the need for a national legal database which would not only help to keep a check on the quality of healthcare but also guide neurosurgeons in their daily practice.

\section{Conclusions}

This survey brings out the practice of defensive neurosurgery in India in view of the apprehension regarding malpractice suits and the desire of physicians to avoid the hassle of medicolegal issues, especially in the private sector. On the other hand, neurosurgeons in the government sector, being less apprehensive, are consequently less knowledgeable and less prepared to deal with medicolegal issues. Thus, the survey findings highlight the gaps in legal awareness and preparedness among neurosurgeons and the consequent need for systematic training in this regard, right from the time of residency.

\section{Acknowledgments}

We would like to acknowledge the help of Ms. Shreya Seth in editing of the manuscript. We would also like to acknowledge Mr. Prasun Acharyya for providing us the statistics regarding malpractice insurance and Mrs. Divya Maghan for providing the statistics regarding malpractice suits.

\section{References}

1. Nahed BV, Babu MA, Smith TR, Heary RF. Malpractice liability and defensive medicine: a national survey of neurosurgeons. PLoS One. 2012;7(6):e39237.

2. Jena AB, Seabury S, Lakdawalla D, Chandra A. Malpractice risk according to physician specialty. N Engl J Med. 2011; 365(7):629-636.

3. Smith TR, Habib A, Rosenow JM, et al. Defensive medicine in neurosurgery: does state-level liability risk matter? Neurosurgery. 2015;76(2):105-114.

4. The Epidemic Diseases (Amendment) Ordinance. The Gazette of India. Accessed September 11, 2020. http://egazette.nic.in

5. Thomas R, Gupta R, Griessenauer CJ, et al. Medical malpractice in neurosurgery: a comprehensive analysis. World Neurosurg. 2018;110:e552-e559.

6. Gupta R, Griessenauer CJ, Moore JM, et al. An analysis of malpractice litigation related to the management of brain aneurysms. J Neurosurg. 2017;127(5):1077-1083.

7. Taylor CL. Neurosurgical practice liability: relative risk by procedure type. Neurosurgery. 2014;75(6):609-613.

8. Steele L, Mukherjee S, Stratton-Powell A, et al. Extent of medicolegal burden in neurosurgery - an analysis of the National Health Service Litigation Authority Database. $\mathrm{Br} J$ Neurosurg. 2015;29(5):622-629.

9. Menger RPP, Storey CM, Nanda A. The Business, Policy, and Economics of Neurosurgery. Lulu Publishing Services; 2018.

10. NPDB. Home page. Accessed September 11, 2020. https:// www.npdb.hrsa.gov/

11. Wheeler RE. Does WestlawNext really change everythingthe implications of WestlawNext on legal research. Law Libr J. 2011;103:359. 
12. Motiwala M, Ajmera S, Akinduro O, et al. How does the media portray neurosurgeons? World Neurosurg. 2019;122: e598-e605.

13. Sun J, Liu S, Liu Q, et al. Impact of adverse media reporting on public perceptions of the doctor-patient relationship in China: an analysis with propensity score matching method. BMJ Open. 2018;8(8):e022455.

14. Hartley BR, Elowitz E. Barriers to the enhancement of effective communication in neurosurgery. World Neurosurg. 2020; 133:466-473.

15. Hartley BR, Hong C, Elowitz E. Communication in neurosurgery-the tower of Babel. World Neurosurg. 2020;133: 457-465.

16. Medical litigation cases go up by $400 \%$, show stats. ETHealthworld.com. Accessed September 11, 2020. http:// health.economictimes.indiatimes.com/news/industry/medical-litigation-cases-go-up-by-400-show-stats/50062328

17. Yadav M, Rastogi PR. A study of medical negligence cases decided by the district consumer courts of Delhi. J Indian Acad Forensic Med. 2015:37:50-55.

18. Johari A. The Indian justice system is too slow, too complex and too costly, says new study. Scroll.in. Accessed September 11, 2020. https://scroll.in/article/866158/the-indian-justicesystem-is-too-slow-too-complex-and-too-costly-says-newstudy

19. Singhal A. Veracity of laws relating to medical malpractice in India. Int J Sci Res Publ. Accessed September 11, 2020. http://www.ijsrp.org/monograph/Veracity_of_laws_relating to_medical_malpractice_in_India-preface.html

20. Choudhry C. Only $15 \%$ medical negligence cases genuine. Times of India. January 18, 2019. Accessed September 11, 2020. https://timesofindia.indiatimes.com/city/gurgaon/only-15medical-negligence-cases-genuine/articleshow/67579198.cms

21. Professional indemnity insurance: buy online, renewal, reviews. Policy Bazaar. Accessed September 11, 2020. https:// www.policybazaar.com/commercial-insurance/professionalindemnity-insurance/

22. Balram Prasad v Kunal Saha \& Ors, Petition No. 290.1999 (Supreme Court of India, 24 October 2013).

23. Nizam's Institute of Medical Sciences v Prasanth S. Dhananka \& Ors, Petition No. 4119.1999 (Supreme Court of India, 14 May 2009).

24. Dr. (Mrs.) Indu Sharma v Indraprastha Apollo Hospital, Petition No. 104.2002 (Supreme Court of India, 16 December 2011).

25. Latifi R, Doarn CR. Perspective on COVID-19: finally, telemedicine at center stage. Telemed J E Health. 2020;26(9): 1106-1109.

26. Perrone G, Zerbo S, Bilotta C, et al. Telemedicine during Covid-19 pandemic: advantage or critical issue? Med Leg J. 2020;88(2):76-77.

27. Telehealth: delivering care safely during COVID-19. HHS. gov. Accessed September 11, 2020. https://www.hhs.gov/ coronavirus/telehealth/index.html
28. Coronavirus disease 2019 (COVID-19). Centers for Disease Control and Prevention. Accessed September 11, 2020. https: //www.cdc.gov/coronavirus/2019-ncov/index.html

29. Affordable Care Act (ACA). HealthCare.gov. Accessed September 11, 2020. https://www.healthcare.gov/glossary/ affordable-care-act/

30. Ambesh P. Violence against doctors in the Indian subcontinent: a rising bane. Indian Heart J. 2016;68(5):749-750.

31. Sekhar MS, Vyas N. Defensive medicine: a bane to healthcare. Ann Med Health Sci Res. 2013;3(2):295-296.

32. Williams PC, Winslade W. Educating medical students about law and the legal system. Acad Med. 1995;70(9):777-786.

33. Cumming A. Good communication skills can mask deficiencies. BMJ. 2002;325(7366):676.

\section{Disclosures}

The authors report no conflict of interest concerning the materials or methods used in this study or the findings specified in this paper.

\section{Author Contributions}

Conception and design: Tandon, Garg, Sharma, Raheja, Katiyar, Kale. Acquisition of data: Garg, Sharma, Raheja, Katiyar, Dash, Bhatnagar, Khullar. Analysis and interpretation of data: Garg, Sharma. Drafting the article: Tandon, Garg, Sharma, Raheja, Raju, Nanda. Critically revising the article: Tandon, Garg, Sharma, Raheja, Katiyar, Raju, Nanda, Kale. Approved the final version of the manuscript on behalf of all authors: Tandon. Statistical analysis: Sharma. Administrative/technical/material support: Dash, Bhatnagar, Khullar, Nanda, Kale. Study supervision: Garg, Kale.

\section{Supplemental Information}

Online-Only Content

Supplemental material is available online.

Supplementary File. https://thejns.org/doi/suppl/10.3171/ 2020.8.FOCUS20592.

\section{Correspondence}

Vivek Tandon: All India Institute of Medical Sciences, New Delhi, India.drtandonvivek@gmail.com. 